\title{
Annealing Effects after Various Thermo-Mechanical Treatments on Microstructure and Mechanical Properties of Wrought Magnesium Alloy ZK60
}

\author{
M.Z. OO ${ }^{a}$, M. JANEČEK ${ }^{b}$, R. KRAL ${ }^{b, *}$ AND L. WAGNER ${ }^{a}$ \\ ${ }^{a}$ Institute of Materials Science and Technology, Clausthal University of Technology, Clausthal-Zellerfeld, Germany \\ ${ }^{b}$ Department of Physics of Materials, Charles University, Prague, Czech Republic
}

\begin{abstract}
The magnesium alloy ZK60 received from Dead Sea Magnesium in direct-chill cast condition was extruded at $T=350^{\circ} \mathrm{C}$ using an extrusion ratio of $\mathrm{ER}=12$. The extruded bars were severely plastically deformed at $250^{\circ} \mathrm{C}$ by either equal channel angular pressing or swaging. While swaging led to similar grain refinements as observed after equal channel angular pressing, yield stress and tensile strength values were by far superior in the swaged material. This result is explained by the unfavourable $45^{\circ}$ texture component of the (0002) pole figure that develops during the massive shear deformation in equal channel angular pressing. Unlike equal channel angular pressing, the grain orientation after swaging is similar as in the as-extruded condition. Annealing at elevated temperatures indicates very low thermal stability of microstructure and mechanical properties in the equal channel angular pressing material while both properties in the swaged microstructure are as stable as in the as-extruded reference.
\end{abstract}

PACS: 81.40.Gh, 81.07.Bc, 61.05.cp

\section{Introduction}

In recent years, research and development studies on magnesium alloys have greatly expanded with regard to weight reduction, energy-saving and environmental protection. Typically, magnesium alloys also offer other attractive properties such as high damping capacity, dimensional stability, good machinability and recyclability [1]. As a relatively new structural material, magnesium and its alloys have demonstrated a significant potential for applications in many industries including automobile, transportation, power tools/equipment and new energy sources. However, the use of magnesium and its alloys has been limited to narrow range because of the limited ductility and poor formability. Limited ductility of $\mathrm{Mg}$ alloys may be due to difficulty of dislocation activity in non-basal slip systems.

Grain refinement in case of $\mathrm{Mg}$ alloys is particularly interesting since it not only offers potential improvements in yield stress [2] and fatigue strength [3, 4] but also in tensile ductility [5]. Therefore, the formability at low temperatures can markedly be improved by microstructure refinement. Besides, fine-grained $\mathrm{Mg}$ alloys possess ductile-brittle transition temperatures (DBTT) significantly lower than their coarse-grained counterparts.

Several methods of severe plastic deformation have been recently developed for refining grain sizes in $\mathrm{Mg}$ alloys down to submicron or even nanocrystalline sizes. These include equal channel angular pressing (ECAP) [4] and high pressure torsion (HPT) [6] as well as rotary swaging (SW) [7].

\footnotetext{
* corresponding author; e-mail: rkral@met.mff.cuni.cz
}

The objective of the present work was to highlight differences in tensile properties and thermal stability of ultrafine grained ZK60 materials produced by ECAP and swaging.

\section{Experimental procedure}

The material used in this investigation was the wrought magnesium alloy ZK60 (Mg-6\% Zn-0.5\% Zr (in wt\%) received as direct chill-cast material from Dead Sea Magnesium, Israel. Material was extruded at $T=$ $350{ }^{\circ} \mathrm{C}$ to an extrusion ratio $\mathrm{ER}=12$ using a $6.3 \mathrm{MN}$ direct extrusion press. From these extrusions, blanks $\left(10 \times 10 \times 100 \mathrm{~mm}^{3}\right)$ for ECAP were machined. ECAP was conducted using a solid die made of tool steel having a square channel with an internal angle of $\Phi=90^{\circ}$ and an angle of $\psi=20^{\circ}$ at the outer arc of curvature. Due to this channel geometry, one pass of ECAP corresponds to a deformation degree of roughly $\varphi=1$ [8]. ECAP was performed using a hydraulic press operating at a speed of $5 \mathrm{~mm} \mathrm{~min}{ }^{-1}$. Before ECAP, the billets were lubricated by $\mathrm{MoS}_{2}$. Pressing was done starting at $T=250^{\circ} \mathrm{C}$ for the first pass and decreasing this temperature by $10^{\circ} \mathrm{C}$ for each of the following passes. The process temperature during ECAP was controlled by means of a thermocouple inserted into a hole drilled close to the deformation zone. Route $B_{\mathrm{C}}$ was applied, i.e. the billets were rotated by $90^{\circ}$ after each pass. 4 passes of $\operatorname{ECAP}(\varphi=4)$ were applied since parallel work [4] has demonstrated that this deformation degree led to the highest values in yield stress and high cycle fatigue strength.

Another part of the extruded blanks was swaged at an initial temperature of $250^{\circ} \mathrm{C}$. A 4-hammer rotary swaging system was used. Swaging was performed in 5 steps 
with an intermediate $5 \mathrm{~min}$ reheating to temperature. During swaging, the as-extruded diameter was reduced from 20 to $9 \mathrm{~mm}$ diameter $(\varphi=1.5)$.

The microstructures after thermo mechanical treatment (TMT) were studied by light microscopy and transmission electron microscopy (TEM). Crystallographic textures were determined by X-ray diffraction and illustrated as (0002) pole figures. The thermal stability of the various TMT conditions was evaluated by light microscopy and tensile testing comparing properties before and after an exposure of $30 \mathrm{~min}$ at temperatures ranging from $150{ }^{\circ} \mathrm{C}$ to $400^{\circ} \mathrm{C}$. Tensile testing was performed at room temperature at an initial strain rate of $10^{-3} \mathrm{~s}^{-1}$.

\section{Results and discussion}

Compared to the coarse as-cast microstructure (Fig. 1a) having a grain size of roughly $100 \mu \mathrm{m}$, further extruding at $350^{\circ} \mathrm{C}$ led to marked grain refinement (Fig. 1b). Apparently, a bi-modal population of almost equiaxed grains consisting of fine grains with an average size of $1-2 \mu \mathrm{m}$ and coarser grains having an average size of more than $10 \mu \mathrm{m}$ was observed. Further drastic grain refinements are seen after ECAP-processing (Fig. 1c) and after swaging as well (Fig. 1d).
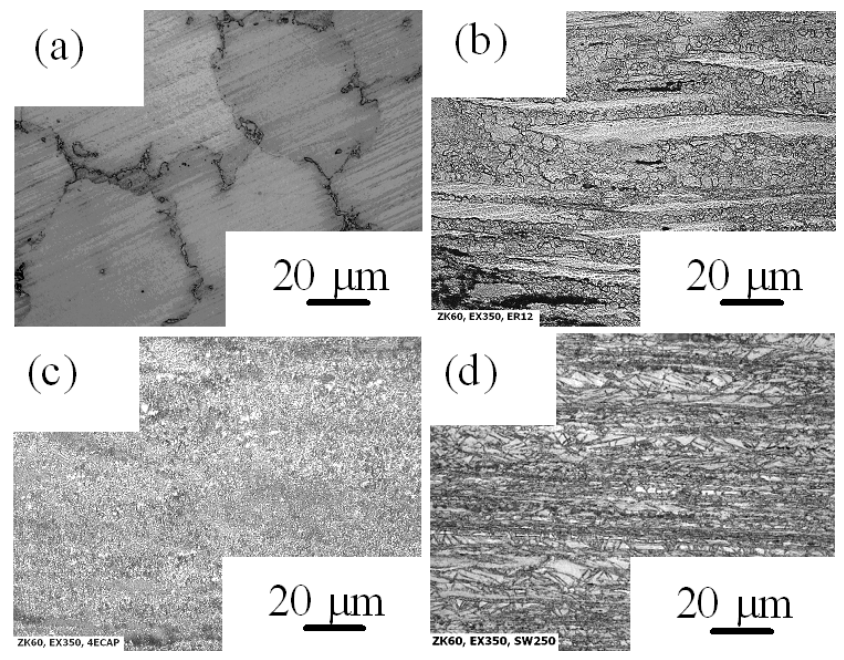

Fig. 1. Light optical microscopy images of the various conditions of ZK60: (a) as-cast, (b) as-extruded, (c) ECAP-ed, (d) swaged.

The corresponding TEM microstructures of the various TMT conditions are illustrated in Fig. 2. Although fine equiaxed grains were formed due to dynamic recrystallization (DRX) during extruding, large elongated non-recrystallized regions were also observed in condition EX (Fig. 2a). The average grain size in the $4 \times$ ECAP-processed material is about $2 \mu \mathrm{m}$ (Fig. 2b) while the grain size is about $1 \mu \mathrm{m}$ in the swaged condition (Fig. 2c).

The drastic increases in yield stress, tensile strength and tensile elongation after extruding, see Table, are explained by the observed strong grain refinement. While

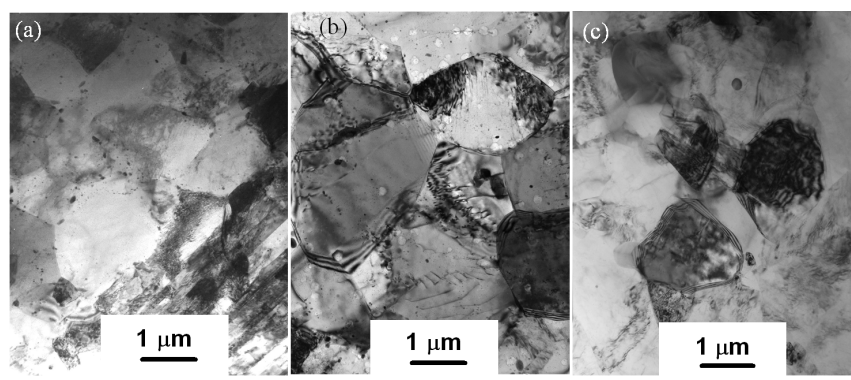

Fig. 2. TEM microstructures of the various conditions of ZK60: (a) extruded, (b) ECAP-ed, (c) swaged.

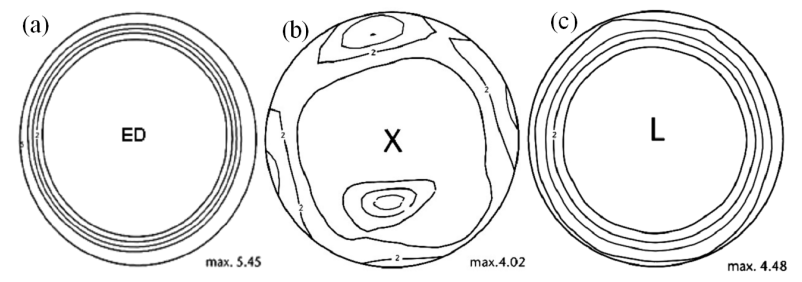

Fig. 3. (0002) pole figures of the various TMT conditions. ED, $\mathrm{X}$, and $\mathrm{L}$ are the main deformation directions during extrusion, ECAP, and swaging, respectively: (a) as-extruded, (b) ECAP-ed, (c) swaged.

$4 \times$ ECAP leads to further increases in yield stress and tensile strength, the highest strength values are clearly observed after swaging. Presumably, the marked differences in strength values between conditions ECAP and SW are caused by differences in crystallographic texture (Fig. 3). Compared to the as-extruded condition (Fig. 3a), the development of a $45^{\circ}$ texture component during ECAP (Fig. 3b) leads to high shear stresses acting on basal planes in axial loading of condition ECAP. Therefore, the yield stress of the ECAP condition is not as high as could be expected from its very small grain size. In contrast, swaging leads to a texture (Fig. 3c) which is of the same beneficial character as observed in the as-extruded condition (Fig. 3a), i.e., only low shear stresses can act on basal planes in axial loading.

The influence of annealing cycles on the changes in microstructure of the various conditions is illustrated in Figs. 4-6. The as-extruded microstructures are still inhomogeneous after annealing at $350^{\circ} \mathrm{C}$. However, an-

TABLE

Tensile properties of the various conditions. Yield strength (YS), ultimate tensile strength (UTS), elongation (El).

\begin{tabular}{c|c|c|c}
\hline \hline & $\begin{array}{c}\text { YS } \\
{[\mathrm{MPa}]}\end{array}$ & $\begin{array}{c}\text { UTS } \\
{[\mathrm{MPa}]}\end{array}$ & $\begin{array}{c}\text { El } \\
{[\%]}\end{array}$ \\
\hline as-cast & 150 & 210 & 7 \\
EX & 290 & 335 & 16 \\
ECAP & 310 & 340 & 18 \\
SW & 390 & 420 & 11
\end{tabular}


nealing at temperatures above $350^{\circ} \mathrm{C}$ (Fig. $4 \mathrm{~d}$ ) leads to homogenized equiaxed microstructures. The initial very fine-grained microstructure of the ECAP-ed condition (Fig. 5a) already somewhat coarsens during 30 min annealing at $300^{\circ} \mathrm{C}$ (Fig. 5b). The further increase in grain size was observed by increasing the annealing temperature from $300^{\circ} \mathrm{C}$ to $350{ }^{\circ} \mathrm{C}$ (Fig. 5c) and $400^{\circ} \mathrm{C}$ (Fig. $5 \mathrm{~d}$ ). On contrary, annealing at $300^{\circ} \mathrm{C}, 350^{\circ} \mathrm{C}$ and $400^{\circ} \mathrm{C}$,

\section{(a)}

(c)

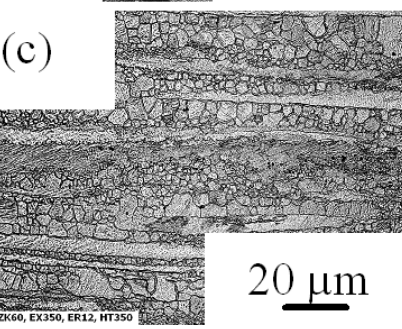

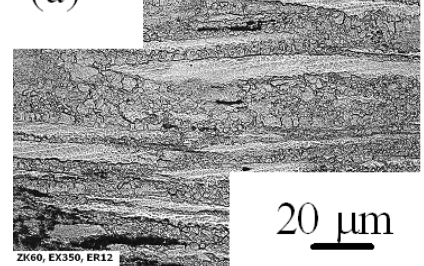

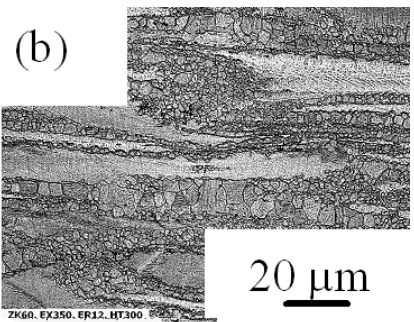

(d)

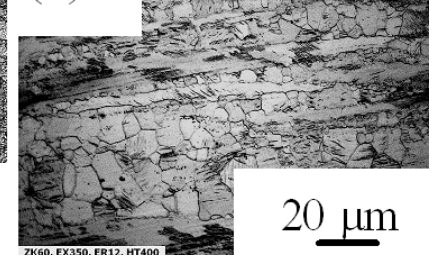

Fig. 4. Annealing effects $(t=30 \mathrm{~min})$ on microstructure changes of extruded material. (a) RT, (b) $T=$ $300{ }^{\circ} \mathrm{C}$, (c) $\mathrm{T}=350{ }^{\circ} \mathrm{C}$, (d) $\mathrm{T}=400^{\circ} \mathrm{C}$.
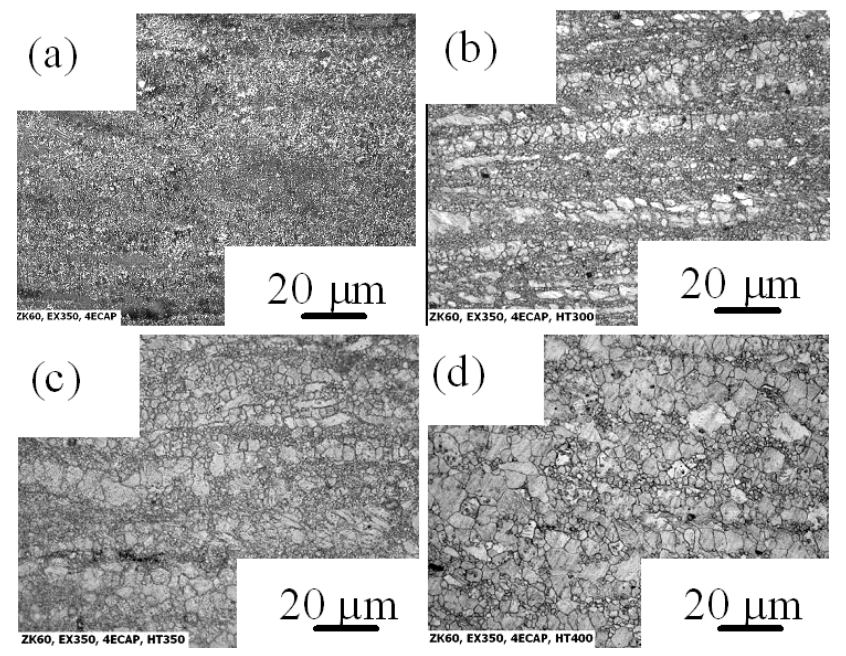

Fig. 5. Annealing effects on microstructure changes in ECAP-ed material (after four passes). (a) RT, (b) $T=$ $300{ }^{\circ} \mathrm{C}$, (c) $\mathrm{T}=350{ }^{\circ} \mathrm{C}$, (d) $\mathrm{T}=400{ }^{\circ} \mathrm{C}$.

respectively, results in similar grain sizes in the case of swaged material, see Fig. 6.

Tensile properties of the various TMT conditions are plotted vs. annealing temperature in Fig. 7 illustrating the changes in yield stress (Fig. 7a) and elongation (Fig. 7b). As indicated in Fig. 7a, the thermal stabil-

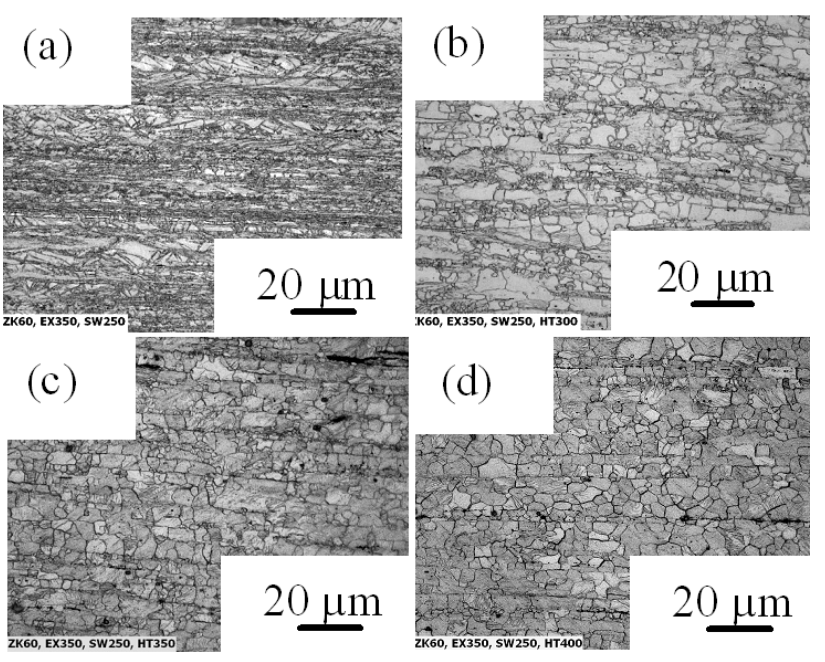

Fig. 6. Annealing effects on microstructure changes in swaged material. (a) RT, (b) $T=300^{\circ} \mathrm{C}$, (c) $T=$ $350^{\circ} \mathrm{C}$, (d) $\mathrm{T}=400{ }^{\circ} \mathrm{C}$.

ities of the extruded and swaged conditions are significantly superior to the ECAP-ed condition. The yield stresses of the ECAP-ed alloy after annealing at temperature above $350^{\circ} \mathrm{C}$ are as low as in the as-cast condition (Table). On the other hand, the very low values of the yield stress of the ECAP-ed material are associated with enhanced elongation after annealing as compared to the as-extruded and swaged materials.

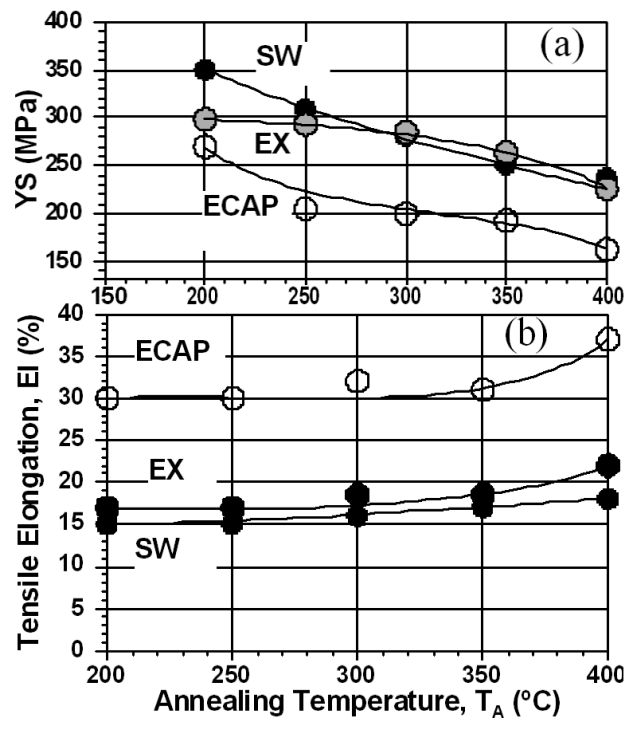

Fig. 7. Tensile properties ((a) yield stress (b) elongation) of the various TMT conditions vs. annealing temperature $(t=30 \mathrm{~min})$.

\section{Conclusions}

Despite similar ultrafine grain sizes, the yield stress and the tensile strength in swaged material are much superior to those in the ECAP-ed material. This is related 
to the massive shear deformation induced during ECAP that leads to a re-orientation of a number of grains with their basal planes aligned at $45^{\circ}$ to the load axis. On the other hand, the highest tensile elongation values were observed in the alloy with the lowest corresponding yield stresses, i.e., in the ECAP-ed material.

\section{Acknowledgments}

This work was financially supported by DAAD-AVCR under the project MEB101106. Partial financial support by GACR, grant no. 109/09/0482 is also acknowledged. One of the authors (M.Z. Oo) would like to thank to Gottlieb Daimler Foundation for financial support during his studies at TU Clausthal.

\section{References}

[1] D. Yin, K. Zhang, G. Wang, W. Han, Mater. Sci. Eng. A 392, 320 (2005).

[2] A. El-Morsy, A. Ismail, M. Waly, Mater. Sci. Eng. A 486, 528 (2008).

[3] M. Shahzad, L. Wagner, Fatig. Eng. Mater. Struct. 33, 221 (2010).

[4] J. Müller, M. Janeček, L. Wagner, Mater. Sci. Forum 584-586, 858 (2008).

[5] H. Takamura, T. Miyashita, A. Kamegawa, M. Okada, J. Alloys Comp. 356-357, 804 (2003).

[6] D. Arpacy, S. Yi, M. Janecek, A. Bakkaloglu, L. Wagner, Mater. Sci. Forum 584-586, 300 (2008).

[7] M.Z. Oo, J. Mueller, M. Janecek, L. Wagner, Int. J. Mater. Res. 100, 374 (2009).

[8] Z. Horita, K. Ohashi, T. Fujita, K. Kaneko, T.G. Langdon, Adv. Mater. 17, 1599 (2005). 